\title{
Dilemma and Strategy for All-English Teaching in the Process of Higher-Education Internationalization
}

\author{
Shiru Zhang \\ College of Communications and Information Engineering, Xi'an University of Science and Technology, Xi'an, \\ Shaanxi, P.R. China \\ zhangshiru@xust.edu.cn
}

Keywords: All-English Teaching, Higher-Education, Internationalization, Bilingual Teaching, Strategy

\begin{abstract}
Higher-education internationalization is introduced. It's stated that all-English teaching is the necessity and future direction. This paper analyzes three kinds of dilemma in the process of high-educati on internationalization: of the fording students, the difficulties in the all-English teaching, and the irregul ar things in current all-English teaching and bilingual teaching. And the reason is the shortage of lecturer s. This paper also gives some useful strategy for dealing with these difficulties. Firstly the enough cognit ion to all-English teaching for the teaching management stuffs, secondly the strategies for all-English tea ching teachers, and the relationship and the coordination among the specialized English, bilingual teachi ng and all-English teaching. The specialized English must be opened, and at least for one semester. The bilingual teaching can be chosen according to the situations of the students. The all-English teaching sho uld be opened to the selected good students according to the university's condition and the English langu age levels of the students, and the number of all-English courses cannot be too many.
\end{abstract}

\section{高等教育国际化中全英文教学的困境和对策}

\author{
张释如 \\ 西安科技大学 通信与信息工程学院，西安，陕西，中国 \\ zhangshiru@xust.edu.cn
}

关键词：全英文教学，高等教育，国际化，双语教学，对策

摘要：简介了高等教育国际化的概念, 论证了全英文教学是高等教育国际化的必然之路和发展 方向, 分析了目前全英文教学的三种困境: 国外留学生听课语言的困难、全英文教学的困难、全 英文教学和双语教学的执行乱象。这些困境的根本原因在于全英文教师的不足。论文还提出解决 目前全英文教学困境的对策: 第一要提高教学管理人员对全英文教学的足够认识, 第二是授课教 师在全英文教学中的有效措施，第三要注意专业外语、双语教学和全英文教学的关系并协调开 课: 专业外语课程必须坚持开设, 至少为一学期; 双语教学可以根据学生的具体情况选择开课, 全英文教学可以根据学校和学生英语水平的具体情况择优选择学生开课, 而且开课门数不宜过 多。

\section{1. 全英文教学是高等教育国际化的必由之路和发展方向}


2015 年 10 月 24 日国务院印发的《统筹推进世界一流大学和一流学科建设总体方案》要求我 国高校建成一批世界一流大学和一流学科。这是我国目前以及今后长期的工作重点和努力方向。 世界一流大学和一流学科意味着我们的高等教育一定要能拿得出手, 能够和世界上其它国家的高 校相比较。可见高等教育的国际化已经成为不可阻挡的潮流 [1]，成为目前教育界研究的热 点。

1980 年美国卡内基高等教育政策研究理事会主席克拉克・科尔（Clark Kerr）提出了 “高等教育 国际化” 这一概念 [2]。21 世纪初一些发达国家便把高等教育国际化纳入到国家和高校的发展 战略中[3]。在过去的 30 多年中，世界政治、经济、科技发生了巨大的变革，国际化的含义也相 应地发生了变化。

简单来说, 高等教育国际化是一个国家高等教育走向国际的发展过程和总体趋势[4]。我国政 策涉及的主要内容归纳起来有四个方面：出国留学、来华留学、中外合作办学以及对外交流与合 作[4]。无论这四个方面中的哪一个都离不开语言的问题，没有语言之间的互通交流，其它都将是 纸上谈兵。因此, 语言的教学, 尤其是英语语言的教授和训练显得尤为重要。要想真正长期立足 于世界一流，必须有英语语言的支撑，因此全英文教学就成为高等教育国际化的必由之路，也是 将来的一个发展方向。全英文教学的英文是 all-English teaching, 有人也称之为 EMI (English Me dium Instruction ） [5], 泛指所有教学活动全部用英语进行的一种教学方式。近年来已经引起相当 多高校的极大重视。

在高等教育国际化的进程中，中国大部分普通高等院校都面临着两方面的问题：第一，中国 学生英语水平太差, 急需提高的问题, 也就是说急需开设全英文课程或双语课程; 第二, 留学生 的汉语水平太差(有的甚至从来没学过汉语或只学了半年), 全中文课程他们无法接受, 必须给他 们开设双语课程或全英文课程。本文将针对这些真实的教学问题进行深入研究并给出解决办法。

\section{2. 目前我国普通高校实施全英文教学的困境}

迄今我国高等教育国际化实践中的一个主要不足之处是：课程与教学国际化的水平还有待进 一步提高 [6]。其中最为困难的就是全英文教学的实施, 这也成为目前的的当务之急。按理说, 我 国双语教学活动开展了十多年, 全英文教学应该问题不大, 但事实却不尽然。就笔者的了解, 目 前我国普通高校全英文教学存在以下乱象或困境:

第一种情况: 目前有些普通高校急于招收留学生, 对留学生的语言基础不予考虑, 致使招来的 留学生根本没有学过汉语, 而他们选修的课程又都是全中文课程, 这给留学生的学习带来巨大困 难。

实际上, 这种高校往往是之前就没有开设过留学生专业所需的双语课程或全英文课程。因此 留学生坐在一句也听不懂的纯汉语教学课堂纯粹是浪费时间, 于是他们就只好不去听课, 全靠自 己在资源非常稀少的环境中找来一些英文的专业内容自学，考试时凑合通过就行了。这样做很明 显留学生的教育质量和学校的名声将会大大受损, 还会影响到以后继续招收留学生, 同时给我国 的高等教育国际化进程带来严重阻力。

第二种情况: 某些普通高等学校没有对招收留学生早做打算, 当看到其它高校都招了留学生, 于是也开始招留学生。针对他们双语教学和全英文教学严重不足, 或者根本没有的情况, 他们采 取应急措施：发放红头文件，开展全英文教学立项活动。

众所周知, 语言的习得是需要坚持不断地长期学习和实践, 要达到能够讲授全英文专业课程 的程度，仅仅靠一个项目的短时间突击是根本不行的。当然作为教学项目对全英文课程的教学方 法、教材、管理措施进行研究是可行的, 但仅靠一至两年的一个项目结题就能允许教师开课, 这 
也未免太仓促了。这样开出来的全英文教学课程能使留学生完全听懂并达到很好的效果吗?

第三种情况：许多学校早就开设了全英文教学课程，但实际考察才知，由于台下都是英语基 础不好的中国学生, 教师也仅仅是采用了全英文教学课件而已。

这种情况和一些双语课程的情况及其类似，在中国本土有，在宝岛台湾也有。之所以挂羊头 卖狗肉是因为要达到学校或教育部门对全英文教学课程门数的要求, 至于实际的执行就没人问及 了。

综上可明显看出：目前全英文教学中存在的种种乱象或困境的根本原因在于师资的匮乏，因 此全英文课程师资的缺少是目前高等教育国际化的最大障碍。

\section{3. 普通高校全英文教学的对策}

\section{1 加强学习提高教学管理人员对全英文教学的足够认识}

高等教育的国际化是一项长期而艰巨的任务，这一点仅从上节所述的全英文教学的一个方面 就能够清楚看到了。开设全英文课程或双语课程中的障碍之一就是教学管理层的政策问题。教学 管理层者的素质不高，对高等教育国际化的重要性没有充分的正确认识。不能把双语教学和全英 文教学放到很重要的层面上, 因此制定的各种政策或教学安排上都对双语教学和全英教学产生了 莫大的阻力。甚至给愿意开设双语课程和全英文课程的教师带来各种困扰。目前很多普通院校的 双语课程很难开出, 主要由于学校的政策引导和相关的配套管理措施不到位。由此也提醒学校组 织部在选聘各种工作人员和领导干部时一定要慎之又慎，严格考察用工人员的综合素质，否则就 会由于教学管理工作人员的素质不够而阻碍学校高等教育国际化的发展进程。

因此，各高校的各级教学管理人员都必须加强学习，提高认识，充分认识到高等教育国际化 的重要性和全英文教学的紧迫性。学校的领导干部和各级管理人员, 必须对高等教育国际化的相 关问题进行及早规划, 统筹安排, 提前为留学生的进驻做好各种准备, 包括全英文教学和双语教 学课程的方方面面。

1）师资的培养和短期培训政策：针对国家急需人才的紧缺专业可以派教师专门到国外培训具 体课程; 对新担任全英文课程的教师进行短期教学口语及发音的短期国内培训, 等等。

2）授课教师的选拔原则：最好是在英语为官方语言的国家学习或工作过半年或一年以上; 口 语和发音需通过选拔小组的考核吗，等等。

3) 培养计划的制定政策和原则: 既不能卡得太死, 也不能放任自流。例如培养计划不能更改 课程，这一条不符合目前技术飞速发展的情况。

4)留学生学位论文的语言规定: 目前许多学校的政策是, 留学生的学位论文除摘要和题目必须 是中英对照外，全文必须是全中文。这个规定有点不太合适。应该鼓励国内的学生写双语学位论 文, 允许留学生写全英文学位论文, 这样对他们参加国际会议, 进行国际学术交流都大有好处。 对他们将来进一步到国外攻读博士更为有利。

5 ）全英文教学课程的细节要求：如教材必须是纯英文教材、或双语教材; 教学课件必须是纯 英文; 考试试卷必须是纯英文 (允许少量偏僻生词的注释); 学生作业和试卷答题可以是双语或 纯英文; 课后答疑可以是中文，等等。

6) 相关的配套管理措施: 如全英文教学的工作量计算, 课时系数一定要高于双语教学较多; 全英文教学课程的质量评价等等。

\section{2 全英文课程中的教学策略}

\section{1）授课教师允许灵活变动}

在保证授课质量不变差的情况下，授课教师可以灵活变动。例如，1）在师资力量不强的情 
况下，可以安排一门课程由多位教师来讲，如每个教师只讲述其中的一节或一章，这样教师压力 也不大，学生也好接受；2）可以邀请临时到学校交流访问的国外知名专家进行针对性专题授 课。

\section{2）课前准备必须充分}

每次授课结束时授课教师一定要给学生布置预习材料, 并发给学生带有音标的生词表灯, 让学生提前进行预习，以便减少停课期间生词和语言方面的障碍。

\section{3 ）选课和上课时间最好灵活}

有必要调整选课机制，允许学生在课程开始的两周或一个月内可以退课或者调整课程。这 样学生就敢于选择双语或全英文课程。

要鼓励那些犹豫是否选学全英文课程的学生走进课堂旁听课程。这就要求全英文课程的讲 课时间最好设置在晚上或周末，能给大量想尝试旁听全英文课程的同学创造有力条件。

4) 全英文课程可以选择纯英文教材或双语教材

全英文课程理应选择纯英文教材，但目前影印版的全英文教材比较少，并不是每门课程都 有; 买进口教材又太贵, 不是所有留学生和国内学生能负担得起的。再者, 考虑到中国学生的英 语水平不高, 留学生的中文水平太差, 可以折中选择国内较好的双语教材。这样也能同时满足留 学生来华留学也想学汉语的愿望。

\section{3 专业外语、双语教学、全英文教学的关系和协调}

目前我国高校在公共英语之后可以开设的和专业相关的英文相关课程有：专业英语、双语教 学、全英文教学课程。

专业外语课程的现状是：以前很多开设一年专业外语课程的学校目前已经把它缩减为半年。 他们只是单纯减少了专业外语课程的授课时数, 并没有同时增加双语教学和全英文教学课程。因 而总体来看，他们此举实际上减弱了英语课程的重要性，这与我国目前急需发展的高等教育国际 化大趋势不相符合。而双语教学课程有些也由于学生英语基础太差或授课教师英语水平不高而天 折，原先轰轰烈烈的双语教学活动也似乎慢慢落下帷幕。正因为如此，目前急需开展的全英文教 学也是步履阑珊。那么, 专业外语、双语教学、全英文教学之间究竟具有什么关系, 应该如何协 调呢?

首先, 专业英语课程是大学生学完两年公共英语课程之后, 是学生从公共英语到双语教学之 间过渡的一门语言类必修课程, 主要让学生学习一些典型的科技英语语法和特点, 以及本专业相 关的英语词汇, 为即将学习的双语教学和全文英文教学课程奠定良好的语言基础。其次, 双语教 学属于专业类课程, 其目的是从纯中文教学到全英文教学的一个过渡, 重点学习的是专业知识。 它在兼顾英文不好学生的同时, 强调了从中文到英文, 英文到中文的翻译, 使学生的思维在中英 文之间来回切换, 因此具有耗时多, 效率不高的特点。最后, 全英文教学也属于专业类课程, 主 要目的是学习专业知识，只是授课语言采用英语而不是汉语而已。

杭州师范大学李颖老师的全英文教学的实践 [5]表明：全英文（EMI）课程对于具备了较好英 语基础、具有较高主观能动性的学生会起到很强的推动和促进作用。显然全英文教学这对于那些 英语基础不好的同学完全不适用，仅仅适用于那些英语基础很好，或英语基础一般但却对课程有 兴趣能够下功夫刻苦学习的学生。

另外，对留学生来讲，较好的办法是听双语课程，因为他们也有学汉语的要求。当学校全英 文课程开出量较小, 而双语课程较成熟开课量也教大时可以请留学生选择双语课程进行学习。

综上所述，高校的专业外语课程必须坚持开设，至少为一学期；双语教学可以根据学生的具 体情况选择开课, 建议每个专业至少开设一门双语课程; 全英文教学可以根据学校和学生英语水 
平的具体情况择优选择学生开课, 而且开课门数不宜过多。如果这三门课程都要开设的话, 建议 开课时间等如表 1 , 这样就能完全做到大学四年英语不断线了。

表 1: 全英文课程和双语课程、专业外语课程的协调开设

\begin{tabular}{|c|c|c|c|c|c|}
\hline & 第 1-4 学期 & 第 5 学期 & 第 6 学期 & 第 7 学期 & 第 8 学期 \\
\hline 必开课程 & 基础英语 & 专业外语 & 双语课程 & 全英文课程 & 文献翻译 \\
\hline 课程性质 & 必修课 & 必修课 & 选修课 & 选修课 & 必修 \\
\hline 选课方式 & / & / & $\begin{array}{c}\text { 全员可选 } \\
\text { (每生至少 } 1 \text { 门) }\end{array}$ & $\begin{array}{c}\text { 择优选修 } \\
\text { (和双语课程每 } \\
\text { 生至少选 } 1 \text { 门) }\end{array}$ & / \\
\hline 开课门数 & l & l & 1-多门课程 & 0-多门课程 & l \\
\hline 可开课程 & / & / & 专业外语 & 双语课程 & / \\
\hline
\end{tabular}

\section{4. 结论}

本文对高等教育国际化进程中的全英文教学课程进行了研究。首先说明了全英文教学课程的 重要性, 讲述了我国普通高等学校全英文教学中的困境, 并进一步给出了相应的解决对策, 如师 资的培养和选用, 教学管理的配套措施, 双语教学、专业外语与全英文教学的协调等。这些对即 将开设全英文教学课程的高校具有一定的参考价值。

\section{项目基金}

2015 年度陕西本科高校省级精品资源共享课程资助（项目编号 94）2015 年度陕西本科高校省级 教学团队（项目编号 47）。2015 provincial high quality resources sharing course in Shaanxi Universit y (Program No.94), 2015 provincial teaching team of Shaanxi University (Program No.47).

\section{参考文献}

[1] 董凌波, 冯增俊, 高等教育国际化发展模式的反思与我国的现实选择 [J], 现代教育管理, 2014, （10）：12-16.

[2] 陈学飞. 高等教育国际化: 跨世纪的大趋势 [M], 福州: 福建教育出版社, 2002: 69 .

[3] 田泽中, 陈君, 王新然, 高等教育国际化概念框架演变趋势研究, 中国成人教育, 2017,

4) : 17-21.

[4] 朱文，张汻，我国高等教育国际化政策变迁述评，高等教育管理，11(2): 116-124， 2017.

[5] 李颖，高校全英文教学效果的实证研究，中国外语，14(1):59-67，2017.

[6] 陆小兵, 王文军, 钱小龙, “双一流”战略背景下我国高等教育国际化发展反思, 高等教育 管理, 12(1):27-34, 2018. 